\title{
Analyzing Service Divide in Academic Libraries for Better Serving Disabled Patrons Using Assistive Technologies
}

\section{Devendra Potnis and Kevin Mallary}

\begin{abstract}
Academic libraries invest thousands of dollars in assistive technologies (AT) for enhancing the delivery of information services to disabled patrons. However, offering AT might not result in their use by the patrons who need them, thereby leading to a service divide. The analysis of qualitative responses, including more than 1,400 quotations, elicited from academic library administrators and librarians in 186 public universities across the United States, reveals that academic libraries encounter 51 challenges related to the knowledge and skills of librarians, hardware and software concerns, institutional factors, finances, and external actors, when serving disabled patrons with AT. Finally, the researchers propose 15 solutions for bridging this service divide.
\end{abstract}

\section{Introduction}

The Americans with Disabilities Act of 1990, otherwise referred to as the ADA, requires that academic institutions in the United States (US) accommodate the special needs of disabled students once they request their institutions' support. ${ }^{1}$ Per the Technology-Related Assistance for Individuals with Disabilities Act of 1988, academic institutions must provide assistive technologies (AT) to disabled students who need them. ${ }^{2}$ An assistive technology refers to "any item, piece of equipment, software program, or product system that is used to increase, maintain, or improve the functional capabilities of persons with disabilities." 3

Typically, multiple units in academic institutions, including disability support services, academic libraries, information technology services, and administrative offices, collectively work with external vendors to purchase AT for serving disabled students. ${ }^{4}$ Although the distribution of internal responsibilities among units might vary, ${ }^{5}$ academic institutions expect hardware and software vendors to submit Voluntary Product Accessibility Templates (VPATs), which explain how their products comply with federal regulations and technical standards. Standards include the ADA, Sections 504 and 508 of the Rehabilitation Act, and the Web Content Accessibility Guidelines. ${ }^{6}$ These compliance documents also help academic institutions ensure that the advertised features of AT meet the information needs of disabled students.

Disabled students primarily use AT to access and use information from print and electronic

\footnotetext{
* Devendra Potnis is an Associate Professor in the School of Information Sciences at the University of Tennessee, Knoxville; email: dpotnis@utk.edu. Kevin Mallary is Instructor in the Department of Communication at Western Carolina University; email: kjmallary@wcu.edu. @2021 Devendra Potnis and Kevin Mallary, AttributionNonCommercial (https://creativecommons.org/licenses/by-nc/4.0/) CC BY-NC.
} 
resources when completing academic tasks and learning. ${ }^{7}$ Hence, academic libraries, the research setting for this study, serve as the most common service delivery touchpoint for AT. ${ }^{8}$ Academic libraries invest thousands of dollars from their budgets in AT for serving disabled patrons, who represent 19 percent of undergraduate students and 12 percent of graduate students in the US. ${ }^{9}$

Investing in AT might not automatically create benefits for disabled patrons, however. Past studies make several suggestions for academic libraries to better serve disabled patrons, with some articles noting that academic libraries are unable to adequately meet those patrons' needs. ${ }^{10}$ After reviewing the accessibility of websites and AT offered by 33 academic libraries, Power and LeBeau ${ }^{11}$ found that only five academic libraries were meeting the information needs of disabled patrons. Mulliken and Atkins ${ }^{12}$ complained, "Many individuals with severe cognitive disabilities... do not receive adequate accommodations to promote success. Limited access to communication technologies, trained staffing, or other basic supports are common." Hernon and Calvert ${ }^{13}$ discussed instances when academic libraries do not adequately serve their disabled patrons and, hence, proposed novel initiatives for academic libraries to improve their services. Miller-Gatenby and Chittenden ${ }^{14}$ identified bibliographic instruction, the accessibility of Web pages, and staff training as the three domains of information service that academic libraries must improve for best helping disabled patrons use assistive technologies. Brannen et al ${ }^{15}$ noted: "The recent Americans with Disabilities Act 25th anniversary has renewed efforts in awareness of serving people with disabilities, reminding libraries that there is always room for improvement of their services within ongoing initiatives." Carter ${ }^{16}$ recommends that academic libraries provide various training opportunities to their staff, including attitudinal awareness, learning about assistive technologies, and delivering services. Such training opportunities can help academic librarians bridge the service divide, which is defined as the inability of a service provider to meet the needs of its consumers. ${ }^{17} \mathrm{~A}$ recent EDUCAUSE survey revealed that 47 percent of disabled students enrolled in colleges and universities across the US perceive that their institutions provide poor, or zero, support in the form of AT. ${ }^{18}$

The goal of this study is to analyze the service divide in academic libraries. Hence, this research inquiry studies the following question: What are the organizational challenges academic libraries encounter when offering information services to patrons with disabilities via AT? The researchers analyze the problem of service divide in academic libraries from an inwardlooking, service-provider perspective, since past research finds that organizational context is the primary influence in patrons' use of technology for meeting their needs. ${ }^{19}$ The researchers argue that academic libraries should identify, analyze, and address their internal challenges to potentially reconcile this service divide in the future.

\section{Theoretical Lens}

The service-dominant logic grounded in the marketing and information systems literature focuses on services provided by organizations. ${ }^{20}$ Per service-dominant logic, a service refers to the process of leveraging resources exchanged among multiple actors to create tangible and intangible benefits for one or more actors. ${ }^{21}$ For instance, the process of serving disabled patrons might involve purchasing AT from vendors, installing those tools in academic libraries, and offering support and guidance to disabled patrons when using AT. This process might require the exchange of various resources: academic institutions invest in AT; academic libraries allocate space for the technologies; and library staff acquire new knowledge and skills for supporting disabled patrons' use of AT. 
Resources are defined as "anything an actor can draw on for support," 22 including tangible goods (for instance, technology) and intangible resources (such as skills). Resources play a key role in enabling organizations like academic libraries to serve disabled patrons. Organizations need knowledge, technological, and institutional resources to offer any type of service. ${ }^{23}$ Knowledge resources include skills and competencies, as well as awareness of service providers' and customers' practices and needs. Technological resources include information and communication technologies, such as the AT considered in this study. Institutional resources include legal policies, organizational culture and norms, and operational procedures. In this study, institutions refer to academic libraries and other campus stakeholders.

Resources dynamically interact with each other through social exchanges to benefit patrons and other stakeholders. ${ }^{24}$ For instance, to serve disabled patrons using AT - a technological resource-staff members, who are institutional resources, would need knowledge-based resources. Staff members would require updated knowledge and skills to keep up with the changing needs of their patrons amid the dynamic landscape of AT. The coordinated integration of resources that stems from institutional policies and procedures creates mutual value for stakeholders and establishes service ecosystems. ${ }^{25}$ Interacting resources bond actors together in a network and promote value creation. ${ }^{26}$ The inability of service providers to orchestrate interactions among resources reinforces the service divide. ${ }^{27}$

\section{Literature Review}

Past studies focus on a range of factors influencing the service divide in academic libraries. Sample factors include innovative ideas, ${ }^{28}$ multiple facets of an innovation strategy, ${ }^{29}$ patrons' demographic and psychological features, ${ }^{30}$ and emerging technologies used by academic libraries. ${ }^{31}$ Leadership, organizational size and complexity, and the environment, are additional factors. ${ }^{32}$ Thus, factors influencing the implementation of AT by academic libraries are not limited to assistive technologies, per se, but they also include organizational and political issues. Most of these studies, however, treat academic libraries as standalone units, which overlooks the reality that libraries belong to larger institutions.

Most research on the service divide in libraries approaches this topic from the user's point of view. For instance, Scupola and Nicolajsen ${ }^{33}$ provide a rationale for involving customers in developing novel services and products in organizations. Drawing upon multidisciplinary literature, they articulate the role of patrons as co-creators and users. Each of the studies they cite advises libraries to look outside when seeking input from patrons, improving existing methods of consumer engagement, and designing new services or improving existing ones. In contrast, this study asks libraries to look inside to identify, analyze, and address the challenges associated with serving patrons. This current approach resembles the look internally strategy suggested by Islam, Agarwal, and Ikeda, ${ }^{34}$ which involves analyzing the constraints faced by libraries and reconciling those challenges with novel ideas for managing the service divide.

Past research on technology-enabled services in academic libraries analyzes the delivery of services and associated networks. ${ }^{35}$ This study traces the challenges experienced by academic libraries when planning, investing in, deploying, and maintaining AT, for offering information services.

Yeh and Walter ${ }^{36}$ propose personnel and financial resources, user participation, collaborations with other libraries, and partnerships with vendors and commercial entities, as four essential resources for proactively avoiding service divide in academic libraries. The present 
empirical research advances this body of knowledge by identifying 51 unique challenges to serving disabled patrons using AT, which can be addressed by managing the dynamic interactions among five key resources.

Academic libraries encounter various challenges when trying to provide disabled patrons with AT: limited funding for AT, lack of awareness of disabled patrons' needs, and the inaccessibility of some electronic resources.

First, securing funding for AT, especially for maintaining and upgrading hardware and software, has long been of concern to academic libraries. ${ }^{37}$ Most academic libraries depend solely on their limited funds, with a select number of libraries receiving funds from disability support services and other institutional sources (examples: competitive grants, students' fees for computing technologies). ${ }^{38}$

Second, selecting AT may prove challenging for academic libraries. Selecting AT requires awareness of the hardware and software tools that disabled patrons need. Awareness of disabled patrons' needs may be problematic because the population is diverse (examples: visual impairments, hearing loss, learning disabilities, mobility impairments) ${ }^{39}$ Compounding their lack of awareness of disabled patrons' needs, academic librarians who do not communicate with disability support services may select inappropriate AT. ${ }^{40}$

Finally, the accessibility of electronic resources (such as library databases, PDFs, and Web pages) can impede academic librarians' provision of AT to disabled patrons. Collections stored in some library databases cannot be retrieved via AT (for instance, screen-reading software), rendering the resources in those databases useless to patrons needing assistance. ${ }^{41}$ Similar to some collections, inaccessible documents (such as PDFs) and Web pages (for instance, LibGuides) published by faculty and staff members cannot be interpreted by AT. ${ }^{42}$

\section{Methodology}

In 2018, the researchers reached out to administrators of academic libraries belonging to 186 public universities, which are among the top 200 academic institutions listed in the U.S. News $\mathcal{E}$ World Report's publication, 2018 Best National Universities. ${ }^{43}$ For each public university, the researchers identified and recorded email addresses of the academic library's dean, director, or head university librarian. To locate this contact information, one of the researchers visited the websites belonging to the academic libraries in these universities and identified 321 librarians responsible for offering information services to disabled patrons, including staff members who had job titles such as access services librarian, AT consultant, and information services and instruction librarian. The researchers emailed their online qualitative survey, developed using Qualtrics, to 507 individuals. This paper reports findings based on the survey questions presented in the appendix. Two weeks later, the researchers followed up with a gentle reminder to potential respondents. They received 50 and 22 complete responses from the administrators and librarians, respectively, with a cumulative response rate of 14.2 percent.

An anonymous survey was employed to make library administrators more comfortable when reporting ineffective and inefficient practices undertaken in their libraries and academic institutions. For instance, most respondents blamed other units on campus for the inability of their academic libraries to serve disabled patrons using assistive technologies. To elicit the most candid feedback, the researchers did not ask respondents to report their institutional affiliations. An online survey is also a cost-effective method for researchers to collect qualitative data. ${ }^{44}$ 
To design their survey, the researchers adopted a systems analysis and design approach, which proposes that planning, analysis, design, implementation, and maintenance and support are the five broad stages of serving patrons via technologies. ${ }^{45}$ Typically, challenges encountered during each of these five stages may adversely affect the delivery of information services to disabled patrons using AT in academic libraries. Hence, we asked respondents to address the challenges encountered when:

1. realizing needs for AT,

2. seeking funds for AT,

3. searching for appropriate AT in the market,

4. evaluating choices of AT available in the market,

5. negotiating agreements with AT manufacturers and suppliers,

6. crafting agreements with vendors,

7. training library staff,

8. designing policies for using AT, and

9. deploying AT in academic libraries (for example, maintaining AT, providing access to AT, helping patrons use AT, helping patrons optimally benefit from using AT).

This survey ascertained the positions of administrators and librarians by affirming respondents' job titles. The researchers also made sure to ask respondents if their libraries offer assistive technologies.

\section{Data Analysis}

The researchers used a combination of qualitative data analysis techniques to make sense of the corpus of data, ${ }^{46}$ which led to three rounds of data analysis. To analyze the challenges encountered, in the first round, they performed a line-by-line analysis of responses to develop hundreds of codes. They tabularized these codes with their interpretations of what respondents meant. One author's extensive expertise in planning, implementing, and maintaining technology solutions in academic institutions helped him better understand respondents' perspectives and any technical jargon used. Another author, who is profoundly deaf, relies on and uses AT for learning and teaching. His experience as a disabled patron of academic libraries at multiple academic institutions contributed to the interpretation of qualitative responses. The intercoder agreement for coding, which lasted for four months, was more than 90 percent. The researchers made sure that codes with the same or similar meanings were grouped.

In the second round, the researchers sorted and synthesized codes by examining them for patterns and relationships, and they also merged overlapping themes. During the third round of data analysis, the researchers engaged in constant comparison. By reading codes multiple times and comparing themes, they kept their biases in check. After crystalizing the themes into five broad clusters, the researchers discovered that the inability of academic libraries to manage resources related to Knowledge \& Skills, Hardware \& Software, Institution, Finance, and External Actors contributes to the service divide.

\section{Findings and Discussion}

Survey respondents reported that, as of 2018, their academic libraries had fiscal budgets of greater than one million dollars. All respondents reported that their academic libraries belong to campuswide systems where information technology services, disability support services, and university administrators, among other units, collaborate to provide information services to 
disabled patrons. In each university, this combination of partners is likely to be unique. Thus, academic libraries are not standalone organizations; instead, they are part of a technical service system. This finding confirms past research on services offered by academic libraries, which found that services cannot be deployed by academic libraries in isolation ${ }^{47}$ As stakeholders within an institution collaborate to deliver services to patrons, they experience conflicts and tensions ${ }^{48}$ thereby reducing the quality of their service.

A majority of the 51 unique challenges reported by library administrators and librarians seem to be complaints about their partners in the technical service system. To retain the anonymity of administrators and librarians, the researchers did not ask respondents to disclose their institutional affiliations.

\section{Knowledge and Skills}

Limited knowledge about disabled patrons' needs is one of the major drawbacks faced by most of the academic libraries in this study (see table 1). One survey respondent, a head of research, teaching, and services, stated: "We don't have any direct interaction with the students and rely on others to refer or promote our services." Several administrators in this study criticized disability support services for sometimes neglecting to communicate the needs of students with documented impairments. Lack of access to disabled patrons' needs makes it challenging for academic libraries to provide tailored information services to them.

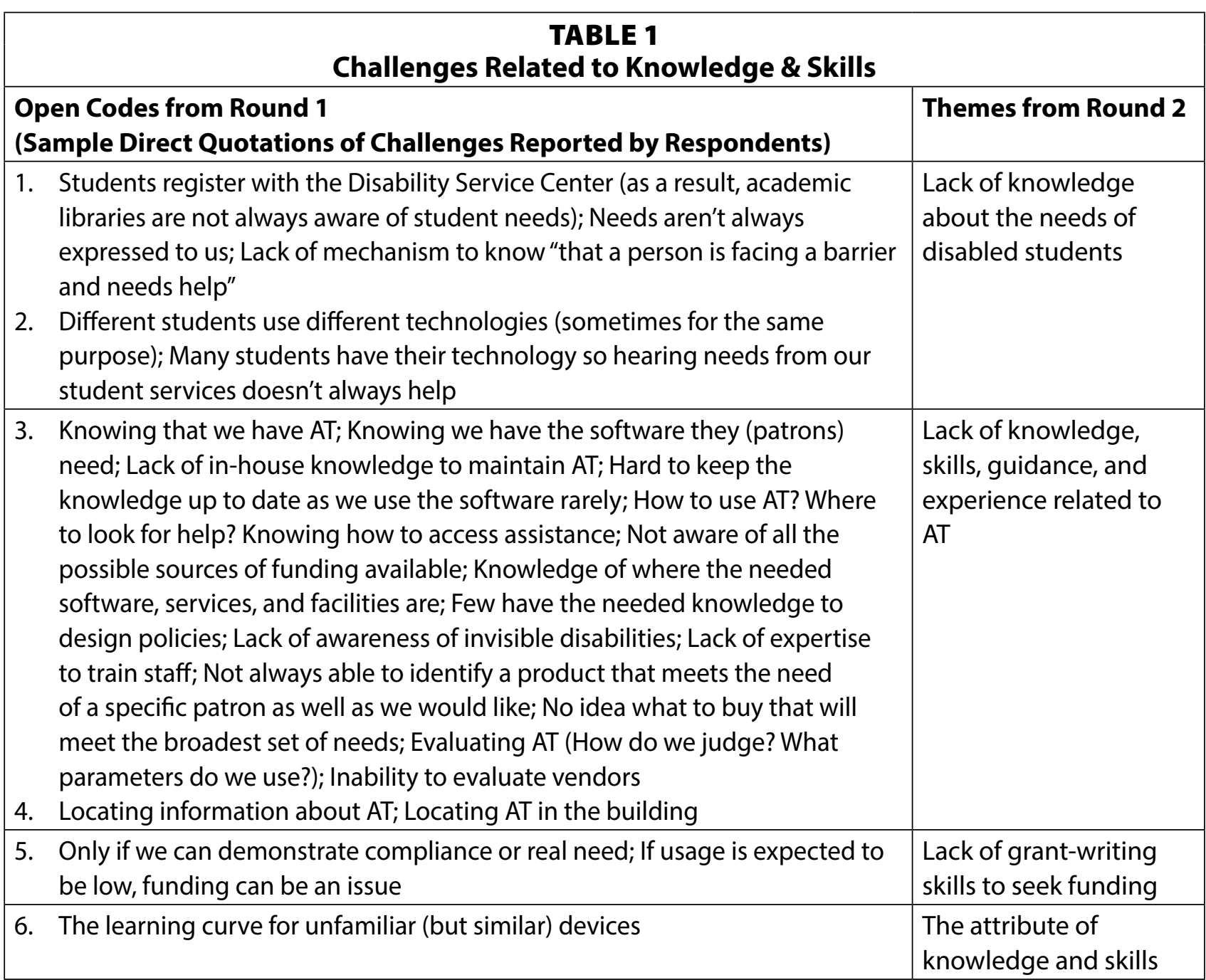


Some administrators in this study did not have staff with appropriate knowledge of AT or related software; they also did not know how to acquire AT or where to locate training opportunities. Additionally, they were generally unaware of policies governing the provision and use of AT, among other concerns. Many administrators reported that some librarians lack awareness of subsidies available for purchasing AT, sources of internal and external funding, types and locations of technologies provided by their institutions, and policies governing the provision and use of AT.

Librarians are increasingly expected to master technology.$^{49}$ However, some administrators in this study reported that staff members in their libraries do not have or receive appropriate training for using or supporting AT. Due to a lack of time and money, librarians in this study are often unable to obtain proper training for professional development. In some cases, the learning curve discourages librarians in this study from attending informative training sessions. Similarly, based on her interviews with librarians at eight academic institutions in Montana, Samson ${ }^{50}$ found that librarians lack the skills and knowledge necessary to meet the information needs of patrons with disabilities. Several librarians in this study confirmed the challenges shared by administrators.

\section{Hardware and Software}

Most respondents in this study admitted to not meeting the needs of their disabled patrons. Some respondents shared the complaints filed by disabled patrons, which reflected those patrons' dissatisfaction with the service. The inability of academic libraries to sustain the AT maintenance process (such as infrequent updates), and the provisions of AT that lack desired features, make it challenging for respondents to meet users' needs (see table 2). Incongruence between the features of AT and patrons' needs, a lack of interoperability among AT and existing library software and hardware, the inconsistent performance of technologies, and noncompliant databases, impede a library's ability to meet disabled patrons' technology needs.

\section{TABLE 2}

Challenges Related to Hardware \& Software

\section{Open Codes from Round 1}

(Sample Direct Quotations of Challenges Reported by Respondents)

7. Keeping it running is a chore-computers age fast; Obsolescence of equipment and need to upgrade software versions

8. Routine maintenance with respect to staff turnover (institutional knowledge goes away as experienced librarians quit the job)

9. Getting people to use the equipment and report when it fails

10. Whenever they re-image the student work stations the assistive technologies software will usually become deactivated or completely disappear; Compatibility with existing hardware; External resources (such as certain subscription databases) that are not compliant with the technologies

11. Adjustable desks break far too often

12. Technologies that are not intuitive or user-friendly; Intuitively being able to operate them since we do not have a trainer assigned to these technologies; Librarians complained it took too long with screen reader and zoom text; they got dizzy; Frustration with using library catalog/online library resources with screen reader

13. Using software that requires individualized configuration (like speech to text) 
A librarian complained: "Many more students on our campus have learning or psychological disabilities than physical disabilities. Yet most of our offerings are geared towards mobility, visual, or auditory [impairments]."

Samson $^{51}$ reports that not all academic libraries mandate the selection of materials in alternative formats, including accessible PDF documents and captioned videos. Although the tools are available, unfriendly user interfaces, as well as software that requires customized configurations for diverse users, further discourages patrons' use of AT in respondents' libraries. Also, assistive technologies that are not intuitive or user-friendly may be unused by patrons with disabilities.

Patrons with similar impairments may have variable needs, which would require different AT. ${ }^{52}$ Thus, the one-size-fits-all approach does not work in this case. A range of AT solutions (such as screenreading software or magnification tools) are available for patrons with similar impairments. ${ }^{53}$ Academic libraries need to consult patrons with similar impairments to understand their actual needs instead of investing in AT based on misguided assumptions.

Patrons can help develop user-centric, technology-based services in libraries. For instance, they can disclose their technical needs or participate in technology solution trials. Survey respondents cited numerous hurdles to meeting users' needs, such as the unavailability of needed AT, as well as limited involvement of students with disabilities (for example: FERPA, low interest among students, lack of recruiting), who could help in trials prior to procuring AT. Disabled students' evolving needs can also leave libraries unaware of the AT that can best serve their users. The technological landscape is rapidly evolving, making it increasingly difficult for libraries to know which AT their patrons might prefer. According to the survey respondents, after making appropriate financial arrangements, sometimes the most beneficial and desired tools are no longer available for purchase. At the same time, too many choices can also confuse or delay the process of acquiring appropriate AT.

\section{Institutional Challenges}

Around 40 percent of the challenges reported by respondents were associated with institutional factors, including bureaucracy, organizational culture, policies, authority, human resource management, space, and marketing and outreach (see table 3). Cui and Jiao ${ }^{54}$ advocate for developing an organizational culture conducive to implementing innovations. However, this study shows that several challenges are posed by the bureaucracies in the academic institutions at large: the selection of AT, the presence of institutional policies, and a lack of human resource management. For instance, because respondents attempting to purchase AT invest a considerable amount of time completing paperwork to receive approval from university administrators, the procurement process is typically tedious and drawn out. The inability of university administrators to evaluate AT is another reason for this delay. Survey respondents reported that funding approval for purchasing AT in public universities with multiple campuses is so time-consuming that, by the time the purchase request is approved, AT with more advanced features may already be on the market. As a result, the technical service system ends up investing in obsolete AT, which may not be ideal for disabled patrons. A manager of AT facilities in a library complained about "not being able to provide all technologies requested." This respondent's library "hoped to provide chair chargers, but because of liability issues, [was] unable to." Patrons' dissatisfaction with, and underutilization of, AT could reinforce the service divide in information services. 


\section{TABLE 3 \\ Institutional Challenges}

\section{Open Codes from Round 1} (Sample Direct Quotations of Challenges Reported by Respondents)

Themes from Round 2

14. Getting buy in from administration and decision by committee taking too much time; Administrative pushback; The process of approval for funding/getting the items needed; Funding approval in an 11-institution system; Purchasing department can sometimes slow matters, as their paperwork is extensive; University Purchasing may not understand that products are not equal

15. Ensuring that everyone understands the need to serve everyone regardless of disability; Reactionary rather than anticipatory; Patience and empathy; Tendency to be restrictive by some

16. Figuring out which department supports what and what that support looks like; Working with campus and department IT to find technologies that will be supported

17. Communicating with our campus' Student Disability Services office; Communication among different library departments, software changes, and updates, and technology obsolescence [for maintaining AT]

18. Designing policy is low on the priority list

19. We do not have policies specific to the use of assistive technologies

20. We did have an outdated, lack of ability-oriented language in our policies

21. Getting user input and feedback is a challenge to making policies

22. An eligible list is provided to the library staff by our office, and students sign the key out (students who are NOT in the list cannot access AT); Securing a time to use the facility; The technologies are kept in a private area that is only accessible to students given the lock codes by the Student Disabilities Resources Center; AT not available throughout the day; Keeping the keys in circulation (students like to keep them overnight)

23. Writing policies that are all-inclusive yet realistic; Decisions over whether the public can use these resources or just our students/faculty/staff; Concerns about equity vs. specific exceptions and accommodations

24. Changes to routine and policy, having to establish new procedures for infrequent requests

25. Generally, we can find funds for things that meet needs, but it is difficult to find the line between our responsibility as a library and the individual's responsibility to provide their own tech; Many students come with their technologies and the library isn't well equipped for more occasional requests

26. Without a disabled person on staff, hard to determine the needs of disabled patrons and create benefits for them through AT

27. Finding someone knowledgeable enough to help them (patrons) with whatever they need; Adequate staffing levels may not always be optimal for staff to leave the desk to go to assistive technology workstation; Limited staff available to train others; Staffing to keep up with alt text re-formatting

28. Lack of staff time to do extensive research for specific technologies; Training staff with vendors first also would have to be scheduled in an understaffed library; Managing time to coordinate uniform training; Difficult to get training for all staff on any technology despite being open for long hours
Organizational culture and processes
Human resource management 


\begin{tabular}{|l|l|}
\hline \multicolumn{2}{|c|}{ Institutional Challenges } \\
\hline $\begin{array}{l}|c| \\
\text { Open Codes from Round 1 } \\
\text { (Sample Direct Quotations of Challenges Reported by Respondents) }\end{array}$ & $\begin{array}{l}\text { Themes from } \\
\text { Round 2 }\end{array}$ \\
\hline $\begin{array}{l}\text { 29. No designated "go-to" staff person; Not having an expert in the technology on } \\
\text { staff has been the biggest challenge for maintaining AT }\end{array}$ & $\begin{array}{l}\text { Human resource } \\
\text { management }\end{array}$ \\
30. Coordinating training with sufficient frequency so that staff skills remain sharp and \\
to cover staffing turnover; Staff training is often left behind other training needs \\
31. Staff forget what they learned because they don't get to use it often enough; \\
$\begin{array}{l}\text { Some of the equipment we have gets used very seldom and it is difficult for staff } \\
\text { to remember how specific programs work }\end{array}$ \\
32. Not wanting to learn another technology; Willingness of staff to attend AT \\
training sessions; Not all our line-staff are comfortable working with patrons with \\
disabilities; Anxiety of using AT; Sometimes librarians cannot accept that invisible \\
disabilities exist; Resistance to change
\end{tabular}

Library administrators complained about not having the authority to deal directly with vendors. Sometimes they are not even involved in negotiating contracts and feel cornered into honoring the unfair terms and conditions to which university administrators have already agreed.

Most survey respondents do not have or seldom follow policies guiding the use of AT. Some of them are forced to adhere to "outdated policies," which are not beneficial for addressing issues related to using AT. According to respondents, policies governing AT sometimes deprived students of timely access to the tools. Tedious authentication processes, policies for reserving AT and associated space, and lack of timely access to locks, codes, or keys for using AT make it difficult for patrons with disabilities to conveniently use them. An instructional technology librarian shed light on this problem: "We want our policies to be as inclusive as possible, but also want to make sure that folks with disabilities have first priority on equipment." Further, this respondent shared the difficulty in "find[ing] a balance between completely unmediated access and keeping everything behind a locked door." As a result, library administrators report circumventing their policies in favor of satisfying patrons' needs. While taking a patron-centric approach is laudable, the lack of policy enforcement can lead to the mismanagement of AT, widening the divide in information services. A growing number of students bring their own devices to use information services. However, this bring your own device practice worsen the service divide, especially when librarians fail to provide the AT that patrons would prefer.

After examining the determinants of service divide in academic libraries, Yeh and Walter ${ }^{55}$ found that incorporating innovation into the established, and often conservative, culture of academic libraries can prove challenging. This study found that many libraries 
do not have a culture that is conducive to serving patrons using AT. For instance, the lack of commitment to fully serving disabled patrons, as well as limited or nonexistent outreach to students with vulnerabilities, paint a negative portrait of libraries. An information services and instruction librarian explains the nature of disinterest among libraries for serving disabled patrons:

" $[\mathrm{H}]$ ad to argue for months to get the bathrooms redone during a massive remodel. They said it was too expensive. Threatened [sic] to report them to the government-it was over a $20 \%$ remodel and legally required to update the code. They BARELY are compliant after they remodeled them. Seems like nobody gave a damn about making [the bathrooms] functional. Our student worker in a chair had to go to a different building to use the restroom for goodness sakes."

As per the survey respondents, physical obstacles further expand the service divide, including insufficient space for housing AT in academic libraries, poorly designed room configurations for ensuring patrons' privacy, and portions of the physical library structure that are noncompliant with the Rehabilitation Act or ADA. Understaffed libraries, limited time for helping patrons use AT, too few staff members dedicated to serving patrons with assistive technologies, and a lack of training pertinent to AT represent some of the institutional challenges faced by librarians in this study. Bierauge ${ }^{56}$ reports that psychological factors, such as librarians' fear of failure and reluctance to take risks when providing new technologies, can negatively impact the implementation of AT. None of the administrators in this study reported these challenges, but librarians did. As indicated by the responses, librarians exhibit certain psychological barriers. Some of them lack interest in serving patrons using AT, do not want to learn how to use new technology, are uncomfortable working with patrons with disabilities, are unwilling to attend training sessions, or cannot accept that invisible disabilities exist. These impediments widen the service divide.

Most administrators in this study, having no direct interaction with students, rely on other campus units to promote the AT offered by their libraries. As a result, they claim that patrons are often oblivious to what is offered by libraries or do not perceive libraries as a place to use AT. Guder, ${ }^{57}$ an ADA specialist at an academic library in the Midwest, warns that, if prospective students are not aware of the AT available at an academic institution, they may attend a different one.

\section{Financial Challenges}

Most academic libraries fund AT through their operating or technology budgets. ${ }^{58}$ More than half of them receive financial support from their institutions' disability support services and other campus units. Financial constraints seem to be one of the most frequently reported challenges to undertaking any new initiatives in libraries. ${ }^{59}$ Information services delivered via AT are not an exception. Respondents in this study describe how budget cuts, competing institutional priorities, lack of budgets dedicated to AT, and reliance on technology fees collected from students make it difficult to serve disabled patrons (see table 4). A panel of 12 assistive technologists, disability service providers, and academic librarians confirm that budgetary constraints can prevent the technical service system from purchasing AT. ${ }^{60}$ As shared by respondents in this study, a lack of funding or external grants reinforces the problem. Also, exorbitant licensing fees for AT can further burden their libraries financially. In terms of the impact of AT, a low return on investment can make it difficult for some respondents' libraries to seek additional funds from administrators in their universities. 


\begin{tabular}{|c|c|}
\hline \multicolumn{2}{|l|}{$\begin{array}{c}\text { TABLE } 4 \\
\text { Financial Challenges }\end{array}$} \\
\hline $\begin{array}{l}\text { Open Codes from Round } 1 \\
\text { (Sample Direct Quotations of Challenges Reported by Respondents) }\end{array}$ & $\begin{array}{l}\text { Themes from } \\
\text { Round } 2\end{array}$ \\
\hline $\begin{array}{l}\text { 37. We had a } 20 \% \text { budget cut last year; Budgetary climate sucks; Purchasing } \\
\text { restrictions; There is no budget line for tech, nearly all our funding is grant-based } \\
\text { 38. Has to come out of existing technology budgets; Constituencies or donors } \\
\text { earmarking money for other items or collection growth instead; Money is an issue, } \\
\text { especially with large building upgrades (like installing automatic doors and ramps) }\end{array}$ & Budget \\
\hline $\begin{array}{l}\text { 39. License fees for some software may limit offering tech over a network in more } \\
\text { of a universal design approach; Obtaining sufficient licensing permissions at a } \\
\text { reasonable price-point } \\
\text { 40. Training in some technologies is extremely expensive }\end{array}$ & Expenses \\
\hline $\begin{array}{l}\text { 41. The spectrum of possible disabilities far outstrips the library's resources to make } \\
\text { accommodations for all; Lack of funding to pay someone else to do it; No external } \\
\text { funding sources or support from the university } \\
\text { 42. Who pays for AT? Campus IT provides a basic deployment of AT, which is audited } \\
\text { at the library level about once per year. So, negotiating exactly who pays for a } \\
\text { purchase invites additional overhead costs in the form of time spent } \\
\text { 43. Financial assistance might have been available through grants }\end{array}$ & Funding \& grants \\
\hline $\begin{array}{l}\text { 44. Low impact for high cost; Unit costs are usually not justifiable with respect to use } \\
\text { demand }\end{array}$ & $\begin{array}{l}\text { Low return on } \\
\text { investment }\end{array}$ \\
\hline
\end{tabular}

One of the drawbacks of being part of a technical service system is that it may be unclear who pays for AT. Gashurov and Kendrick ${ }^{61}$ found that few on-campus units at the City University of New York, Cornell University, and Columbia University were willing to share personnel and financial resources related to AT. Administrators in this study were sometimes caught off guard when charged for expensive AT or associated fees. They further complain that negotiating who exactly pays for AT invites additional overhead costs in the form of time spent, which deters the negotiation among units of the technical service system.

\section{External Actors}

Survey respondents indicated that false claims made by vendors, incorrect VPATs (in other words, self-disclosing documents produced by vendors evaluating the compliance of AT with federal regulations), disagreements with vendors, poor quality of AT supplied by vendors, and discrepancies in the information provided by sales representatives versus the actual performance of AT, are some of the major hurdles when investing in AT (see table 5).

The external pressure to comply with ever-changing legal regulations further accentuates the need for academic libraries to seek guidance from external actors. Hence, it becomes essential that libraries make vendors of electronic resources (like databases, e-books, and videos) aware of their need for accessible resources. ${ }^{62}$ Also, libraries should ensure that the electronic resources provided are fully accessible via AT. However, as the survey respondents indicated, a lack of timely access to technology consultants, libraries in peer institutions, and online and print support materials place administrators at a disadvantage when dealing with vendors. 


\begin{tabular}{|l|l|}
\hline \multicolumn{2}{|c|}{ TABLE 5 } \\
\hline \multicolumn{2}{|c|}{ Challenges Related to External Actors } \\
\hline $\begin{array}{l}\text { Open Codes from Round 1 } \\
\text { (Sample Direct Quotations of Challenges Reported by Respondents) }\end{array}$ & $\begin{array}{l}\text { Themes from } \\
\text { Round 2 }\end{array}$ \\
\hline $\begin{array}{l}\text { 45. Some vendors claim the product is accessible when it is not; Vendors are writing } \\
\text { them (contract and agreements) when they have no idea what they are doing! } \\
\text { VPATs do not always seem to be correct; Sales reps sometimes make promises that } \\
\text { the tech doesn't meet }\end{array}$ & Vendors \\
$\begin{array}{l}\text { 46. Finding accessible materials (journals, video, etc.) to purchase } \\
\text { 47. Inability to test products before committing to purchase them; } \\
\text { 48. Reluctance to agree to accessibility language in a license; Some vendors claim } \\
\text { that accessibility is out of their control; Vendor pushback on making interfaces } \\
\text { accessible }\end{array}$ & \\
\hline $\begin{array}{l}\text { 49. Consultants: Getting help from people who know the technology; Technical } \\
\text { support for selected products }\end{array}$ & $\begin{array}{l}\text { Supporting } \\
\text { Community }\end{array}$ \\
$\begin{array}{l}\text { 50. Professional Network: Attending the CSUN Conference helps with cutting edge } \\
\text { hard/software }\end{array}$ & \\
\hline 51. Compliance: Need to abide by state laws, so we always have to change something & Government \\
\hline
\end{tabular}

\section{Interpreting the Challenges}

It is important to note that the five types of challenges identified in this current study are not based on the statistics of disabled patrons' use of AT in academic libraries. Survey respondents relied on their memory when sharing their experiences, opinions, and perceptions of the service divide in their libraries. The five types of challenges show that the barriers to serving the disabled patrons are not just limited to features of AT, but they also include other contextual factors such as organizational and political issues. For instance, the largest number of challenges (that is, around $40 \%$ ) are associated with the institution, including organizational policies, culture and norms, and procedures employed by academic libraries and other academic units with whom they partner to serve disabled patrons. Competencies of librarians and library administrators were perceived as barriers to implementing AT by the administrators and librarians, respectively. This fact suggests the lack of sufficient dialogue on expectations, outcomes, or capabilities of administrators and librarians when serving disabled patrons. Federal regulations and institutional rules guide the interactions of academic libraries with external actors, and they affect the service offered to disabled patrons using AT. For instance, ADA and related regulations, VPATs, and contracts negotiated with vendors determine the degree to which academic libraries are able to meet the needs of disabled patrons.

The dominant role of contextual factors in influencing the ability of academic libraries to serve disabled patrons using AT justifies the researchers' inward-looking, service-provider perspective. Further, it bolsters the argument presented in this paper that academic libraries cannot bridge the service divide unless they identify, analyze, and address the organizational challenges. However, several institutional challenges identified by the respondents are partially beyond the control of libraries since these challenges are associated with, and perhaps caused by, other academic units on campus. 


\section{Implications}

The fundamental rule in any service industry is to provide customers with the service they need. However, the ADA and other policies, such as VPATs, require academic libraries to maintain a certain quality of service when providing AT to disabled patrons. The challenges revealed in this study make it evident that the libraries represented are unable to fully meet their patrons' needs.

The challenges reported by respondents affect practice in several ways. For instance, if students with disabilities cannot be contacted, academic libraries are unable to fully understand their needs and serve them effectively using AT. Several librarians in this study are dissatisfied with the limited and obsolete features of assistive technologies installed in their libraries, which adversely affect the quality of service offered to disabled students. Policies and directives guiding the provision of AT makes it difficult for librarians to deal with the host of issues encountered when serving disabled patrons. Also, hardware and software installed in library spaces deemed inaccessible to disabled patrons present barriers to their use. As a result, survey respondents report students' growing dissatisfaction with academic libraries' inability to meet disabled patrons' needs.

Resources cannot be used in isolation. ${ }^{63}$ To benefit patrons, service providers should be able to manage the dynamic interactions among resources. The 51 challenges confirm the inability of technical service system partners to manage the dynamic interactions among the five key resources, which is essential to offering information services to disabled patrons via AT. We propose 15 solutions that libraries might find useful for addressing some of the challenges (see table 6).

\begin{tabular}{|l|l|l|}
\hline \multicolumn{3}{|c|}{ Proposed Solutions for Bridging the Service Divide } \\
\hline$\#$ & Solutions for academic libraries to bridge the service divide & $\begin{array}{l}\text { Types of challenges } \\
\text { that can be } \\
\text { addressed }\end{array}$ \\
\hline $\mathbf{1}$ & $\begin{array}{l}\text { Academic libraries can proactively build, and periodically update, in-house } \\
\text { databases that contain (a) contact details of students with disabilities } \\
\text { and their needs, (b) AT and related services available across campus, and } \\
\text { (c) contact details of employees across campus who possess expertise } \\
\text { in serving patrons with disabilities using AT. Libraries need to regularly } \\
\text { gather and share this information with concerned stakeholders in their } \\
\text { institutions. }\end{array}$ & $\begin{array}{l}\text { - Knowledge \& Skills } \\
\text { Institutional }\end{array}$ \\
\hline $\mathbf{2}$ & $\begin{array}{l}\text { Support the professional development of librarians. Library administrators } \\
\text { need to encourage librarians to learn new skills, including grant writing } \\
\text { and negotiation, and provide their librarians with opportunities to receive } \\
\text { training. Librarians can learn these skills online or by attending workshops } \\
\text { and seminars, either held on campus or at conferences. }\end{array}$ & - Knowledge \& Skills \\
\hline $\mathbf{3}$ & $\begin{array}{l}\text { Develop and regularly update self-paced training modules and materials } \\
\text { for librarians to learn about different aspects of serving patrons with } \\
\text { disabilities using AT. These training modules should always be available } \\
\text { and accessible via different modes (e.g., mobile devices) so librarians } \\
\text { can complete them at times (e.g., on weekends) and in locations most } \\
\text { convenient to them. }\end{array}$ & $\begin{array}{l}\text { - Knowledge \& Skills } \\
\text { Institutional }\end{array}$ \\
\hline
\end{tabular}




\begin{tabular}{|c|c|c|}
\hline \multicolumn{3}{|c|}{ TABLE 6} \\
\hline \# & Solutions for academic libraries to bridge the service divide & $\begin{array}{l}\text { Types of challenges } \\
\text { that can be } \\
\text { addressed }\end{array}$ \\
\hline 4 & $\begin{array}{l}\text { Provide formal communication channels (e.g., documents on SharePoint, } \\
\text { library websites, blogs, wikis) to employees for sharing expertise and ideas } \\
\text { for better serving patrons with disabilities. Employees can document and } \\
\text { share their best practices for serving patrons with disabilities using AT. }\end{array}$ & $\begin{array}{l}\text { - Knowledge \& Skills } \\
\text { - Institutional }\end{array}$ \\
\hline 5 & Design and update necessary procedures for routinely maintaining AT. & $\begin{array}{l}\text { - Hardware \& Software } \\
\text { - Financial } \\
\text { - External Actors }\end{array}$ \\
\hline 6 & $\begin{array}{l}\text { Attempt to join institutional teams responsible for procuring AT from } \\
\text { vendors. }\end{array}$ & $\begin{array}{l}\text { - Hardware \& Software } \\
\text { - External Actors }\end{array}$ \\
\hline 7 & $\begin{array}{l}\text { Identify bureaucratic bottlenecks that exist within institutions in order to } \\
\text { mitigate potential pushback from higher authorities when purchasing and } \\
\text { deploying AT so that future delays can be minimized or avoided. }\end{array}$ & $\begin{array}{l}\text { - Institutional } \\
\text { - Financial }\end{array}$ \\
\hline 8 & $\begin{array}{l}\text { Establish the following strategic priorities: } \\
\text { - Enhance the type, level, and quality of service to patrons with disabilities } \\
\text { - Commit to hiring a disabled library staff member } \\
\text { - Better equip staff (e.g., policy design, training opportunities) to deal with } \\
\text { any issues that might arise when serving patrons with disabilities }\end{array}$ & - Institutional \\
\hline 9 & $\begin{array}{l}\text { Continue making spaces within libraries ADA-compliant so that patrons } \\
\text { with disabilities can more easily navigate them and use AT as needed. }\end{array}$ & - Institutional \\
\hline 10 & $\begin{array}{l}\text { Offer cultural sensitivity training and publish related materials for } \\
\text { librarians so that they best understand their responsibility to serve all } \\
\text { patrons, regardless of disability. }\end{array}$ & - Institutional \\
\hline 11 & $\begin{array}{l}\text { Design comprehensive, inclusive policies for addressing operational issues } \\
\text { that may arise when providing AT to patrons with disabilities. }\end{array}$ & - Institutional \\
\hline 12 & $\begin{array}{l}\text { Actively promote AT and related information services so that students and } \\
\text { other patrons know they are available. }\end{array}$ & $\begin{array}{l}\text { - Institutional } \\
\text { - Financial } \\
\text { - External Actors }\end{array}$ \\
\hline 13 & $\begin{array}{l}\text { Implement a physical suggestion box, in addition to an electronic form on } \\
\text { the library's website, so that patrons can anonymously provide feedback } \\
\text { on their experiences and make suggestions for improving the quality of } \\
\text { service delivered via AT. }\end{array}$ & $\begin{array}{l}\text { - Knowledge \& Skills } \\
\text { - Hardware \& Software } \\
\text { - Institutional }\end{array}$ \\
\hline 14 & $\begin{array}{l}\text { Explore innovative partnerships with both on-campus and external } \\
\text { stakeholders for the purposes of (a) sharing one-time and recurring costs } \\
\text { of providing AT to patrons with disabilities, (b) training employees, (c) } \\
\text { troubleshooting problems with AT, (d) ensuring compliance with legal } \\
\text { mandates, and (e) scanning the environment for ideas and practices } \\
\text { related to serving patrons with disabilities. }\end{array}$ & $\begin{array}{l}\text { - Knowledge \& Skills } \\
\text { - Institutional } \\
\text { - Financial } \\
\text { - External Actors }\end{array}$ \\
\hline 15 & $\begin{array}{l}\text { Establish and use key performance indicators for measuring the return on } \\
\text { investment in AT. Sample indicators may include the number of patrons } \\
\text { served, the number of AT checked out, and the number of hours AT are } \\
\text { used, among others. }\end{array}$ & $\begin{array}{l}\text { - Institutional } \\
\text { - Financial }\end{array}$ \\
\hline
\end{tabular}


Several responses (see table 3 on Institutional Challenges and table 4 on Financial Challenges above) suggest that the service divide reported by respondents in this study might not be limited to AT alone, partly because institutional factors (such as politics, limited professional development, insufficient institutional support, and lack of collaboration) can lead to a divide when serving patrons using any technology. Solutions proposed for bridging the service divide can also help academic libraries better serve patrons using technologies beyond AT, since 13 out of 15 solutions are related to addressing the institutional challenges (see table 6) that lead to the service divide. While the institutional challenges are indeed numerous, formidable, and partially beyond academic libraries' control, we believe that, by adopting our proposed solutions for addressing these barriers, academic libraries can best serve disabled patrons.

\section{Conclusion, Limitations, and Future Research}

Addressing our research question, academic libraries encounter numerous barriers when delivering information services to disabled patrons (see Findings). This study confirms that simply offering assistive technologies does not always translate into their use. Findings based on the service-provider perspective can guide academic libraries in planning and implementing more patron-centered services. Our proposed solutions can help facilitate optimal engagement among multiple institutional stakeholders.

Due to the limited resources available for this research, the researchers narrowed the scope of this study to academic libraries in the U.S. News $\mathcal{E}$ World Report's top 200 universities. This study also did not ask for specific dollar amounts invested by academic libraries in AT. Since this study focuses on the service-provider perspective, it does not define the use of $A T$ from the user's perspective.

In the future, the degree to which the 51 challenges affect the service offered to patrons using AT can be compared across diverse academic libraries that differ in terms of their budgets, staffing, and the number of disabled patrons enrolled in their institutions. This comparison would be useful in developing more tailored guidance for academic libraries.

\section{Acknowledgment}

We would like to thank all the librarians and library administrators who participated in our study. 


\section{APPENDIX. Abridged Survey Instrument}

1. Please select the type of your library.
a. Academic
b. Public
c. School
d. Special
e. Other:

2. What is the operating budget of your library in this fiscal year?
a. Less than $\$ 25,000$
b. $\$ 25,000-\$ 50,000$
c. $\$ 50,001-\$ 100,000$
d. $\$ 100,001-\$ 200,000$
e. $\$ 200,001-\$ 500,000$
f. $\$ 500,001-\$ 1$ million
g. Greater than $\$ 1$ million

3. What is your job title?

4. Are you one of the administrators in your library?
a. Yes
b. No
c. Other:

5. Does your library have any assistive technologies?
a. Yes
b. No
c. Don't know
d. Other:

6. What is the typical duration of finalizing a specific assistive technology in your library?

7. Can you identify all possible challenges, barriers, and issues your library faced when...?

a. Realizing the need to have assistive technologies in libraries:

b. Seeking funds for purchasing assistive technologies:

c. Searching for assistive technologies in the marketplace:

d. Evaluating various choices available in the marketplace:

e. Negotiating with vendors:

f. Crafting agreement or service contract with vendors:

g. Training library staff for serving disabled patrons using newly purchased assistive technologies:

h. Designing library policies for disabled patrons when using assistive technologies:

i. Deploying assistive technologies in the library:

j. Operating/maintaining assistive technologies:

k. Providing access to disabled patrons:

1. Helping patrons use assistive technologies:

m. Helping patron benefit from assistive technologies:

n. Other: 


\section{Notes}

1. Michelle Brannen, Steven Milewski, and Thura Mack, "Providing Staff Training and Programming to Support People with Disabilities: An Academic Library Case Study," Public Services Quarterly 13, no. 2 (2017); Ravonne Green, "Assistive Technology and Academic Libraries: Legal Issues and Problem Resolution," Journal of Access Services 6, no. 1/2 (2009).

2. Green, "Assistive Technology and Academic Libraries."

3. "What is AT?" (2019), accessed 5 February 2020, https://www.atia.org/at-resources/what-is-at/.

4. Green, "Assistive Technology and Academic Libraries"; Mary Cassner, Charlene Maxey-Harris, and Toni Anaya, "Differently Able: A Review of Academic Library Websites for People with Disabilities," Behavioral $\mathcal{E}$ Social Sciences Librarian 30, no. 1 (2011); Peter Hernon and Philip Calvert, Improving the Quality of Library Services for Students with Disabilities (Westport, CT: Libraries Unlimited, 2006).

5. Brannen, Milewski, and Mack, "Providing Staff Training and Programming to Support People with Disabilities."

6. "Best Practices in Accessibility for Purchasing and Marketing E-Resources: Purchasing and VPAT \& GPAT Statements," City University of New York (CUNY), 2019, accessed August 28, 2020, https://guides.cuny. edu/c.php?g=393890.

7. Manorama Tripathi and Archana Shukla, "Use of Assistive Technologies in Academic Libraries: A Survey," Assistive Technology 26, no. 2 (2014); Iris Xie et al., "Using Digital Libraries Non-visually: Understanding the Help-seeking Situations of Blind Users," Information Research 20, no. 2 (2015).

8. Cassner, Maxey-Harris, and Anaya, "Differently Able"; Hernon and Calvert, Improving the Quality of Library Services for Students with Disabilities.

9. National Center for Education Statistics, Digest of Education Statistics, 2017 (Washington, DC: US Department of Education, 2019), https://nces.ed.gov/programs/digest/d17/ch_3.asp.

10. Brannen, Milewski, and Mack, "Providing Staff Training and Programming to Support People with Disabilities"; Cassner, Maxey-Harris, and Anaya, "Differently Able"; Hernon and Calvert, Improving the Quality of Library Services for Students with Disabilities; Catherine J. Carter, "Providing Services for Students with Disabilities in an Academic Library," Education Libraries 27, no. 2 (2004); Katherine Miller-Gatenby and Michele Chittenden, "Reference Services for All: How to Support Reference Service to Clients with Disabilities," Reference Librarian 33, no. 69/70 (2000); Adina Mulliken, "There Is Nothing Inherently Mysterious about Assistive Technology: A Qualitative Study about Blind User Experiences in US Academic Libraries," Reference \& User Services Quarterly 57, no. 2 (2017); Rebecca Power and Chris LeBeau, "How Well Do Academic Library Web Sites Address the Needs of Database Users with Visual Disabilities?" Reference Librarian 50, no. 1 (2009).

11. Power and LeBeau, "How Well Do Academic Library Web Sites Address the Needs of Database Users with Visual Disabilities?"

12. Adina Mulliken and Ann Atkins, "Academic Library Services for Users with Developmental Disabilities," Reference Librarian 50, no. 3 (2009): 276.

13. Hernon and Calvert, Improving the Quality of Library Services for Students with Disabilities.

14. Miller-Gatenby and Chittenden, "Reference Services for All."

15. Brannen, Milewski, and Mack, "Providing Staff Training and Programming to Support People with Disabilities," 61.

16. Carter, "Providing Services for Students with Disabilities in an Academic Library."

17. Shirish Srivastava and G. Shainesh, "Bridging the Service Divide through Digitally Enabled Service Innovations: Evidence from Indian Healthcare Service Providers," MIS Quarterly 39, no. 1 (2015).

18. J. Galanek, C. Gierdowski, and Christopher Brooks, ECAR Study of Undergraduate Students and Information Technology (Boulder, CO: EDUCAUSE Center for Analysis and Research, 2018).

19. Devendra Potnis et al., "Factors Influencing Undergraduate Use of E-books: A Mixed Methods Study," Library \& Information Science Research 40, no. 2 (2018).

20. Stephen Vargo and Robert Lusch, "The Four Service Marketing Myths: Remnants of a Goods-based, Manufacturing Model," Journal of Service Research 6, no. 4 (2004).

21. Michael Barrett et al., "Service Innovation in the Digital Age: Key Contributions and Future Directions," MIS Quarterly 39, no. 1 (2015).

22. Vargo and Lusch, "The Four Service Marketing Myths."

23. Stephen Vargo and Robert Lusch, "Why 'Service'?" Journal of Academic Marketing Science 36, no. 1 (2008).

24. Stephen Vargo and Robert Lusch, "Institutions and Axioms: An Extension and Update of service-dominant logic," Journal of Academic Marketing Science 44, no. 1 (2016).

25. Robert Lusch and Stephen Vargo, "Evolving to a New Dominant Logic for Marketing," Journal of Market- 
ing 68, no. 1 (2004).

26. Robert Lusch and Satish Nambisan, "Service Innovation: A Service-dominant Logic Perspective," MIS Quarterly 39, no. 1 (2015).

27. Srivastava and Shainesh, "Bridging the Service Divide through Digitally Enabled Service Innovations."

28. Holt Zaugg and Melissa Warr, "Integrating a Creativity, Innovation, and Design Studio within an Academic Library," Library Management 39, no. 3/4 (2018).

29. Jennifer Rowley, "Should Your Library Have an Innovation Strategy?" Library Management 32 (2011).

30. Ada Scupola and Hanne Westh Nicolajsen, "Service Innovation in Academic Libraries: Is There a Place for the Customers?" Library Management 31, no. 4/5 (2010).

31. H. Frank Cervone, "Emerging Technology, Innovation, and the Digital Library," OCLC Systems E Services: International Digital Library Perspectives 26, no. 4 (2010): 239-42.

32. Ronald Jantz, "Innovation in Academic Libraries: An Analysis of University Librarians' Perspectives," Library E Information Science Research 34, no. 1 (2012).

33. Scupola and Nicolajsen, "Service Innovation in Academic Libraries."

34. Anwarul Islam, Naresh Kumar Agarwal, and Mitsuru Ikeda, "Knowledge Management for Service Innovation in Academic Libraries: A Qualitative Study," Library Management 36, no. 1/2 (2015).

35. Zaugg and Warr, "Integrating a Creativity, Innovation, and Design Studio within an Academic Library."

36. Shea-Tinn Yeh and Zhiping Walter, "Determinants of Service Innovation in Academic Libraries through the Lens of Disruptive Innovation," College E Research Libraries 77, no. 6 (2017).

37. Ravonne Green and Diane Gillespie, "Assistive Technologies in Academic Libraries: A Preliminary Study," Libraries and the Academy 1, no. 3 (2001); Suzanne Brown and LeiLani Freund, Services for Users with Disabilities (Chicago, IL: Association of Research Libraries, 2010), www.arl.org/resources/pubs/spec/.

38. Brown and Freund, Services for Users with Disabilities.

39. Brannen, Milewski, and Mack, "Providing Staff Training and Programming to Support People with Disabilities"; Cordelia Riley, "Training for Library Patrons Who Are Hard-of-hearing," Journal of Access Services 6, no. 1/2 (2009); Michael Saar and Helena Arthur-Okor, "Reference Services for the Deaf and Hard-of-hearing," Reference Services Review 41, no. 3 (2013).

40. Mulliken and Atkins, "Academic Library Services for Users with Developmental Disabilities"; Christopher Guder, "Equality through Access: Embedding Library Services for Patrons with Disabilities," Public Services Quarterly 6, no. 2/3 (2010); Karen Kaufmann, Geraldine Perez, and Marshall Bryant, "Reaching Shared Goals in Higher Education: A Collaboration of the Library and Disability Support Services," Library Leadership \& Management 32, no. 2 (2018); Sue Samson, "Best Practices for Serving Students with Disabilities," Reference Services Review 39, no. 2 (2011).

41. Xie et al., "Using Digital Libraries Non-visually"; Kelly Dermody and Norda Majekodunmi, "Online Databases and the Research Experience for University Students with Print Disabilities," Library Hi Tech 29, no. 1 (2011); Adina Mulliken and Kerry Falloon, "Blind Academic Library Users' Experiences with Obtaining Fulltext and Accessible Full-text of Books and Articles in the USA," Library Hi Tech 37, no. 1 (2019); Rebecca Marrall and Nora Burmeister, "Conducting the Accessibility Audit: How One Academic Library Identified Barriers for Patrons with Disabilities" (2016); Nuzhah Sahib, Anastasios Tombros, and Tony Stockman, "Evaluating a Search Interface for Visually-impaired Searchers," Journal of the Association for Information Science and Technology 66, no. 11 (2015); Kristina Southwell and Jacquelyn Slater, "An Evaluation of Finding Aid Accessibility for Screen Readers," Information Technology and Libraries 32, no. 3 (2013); Jennifer Tatomir and Joanna Tatomir, "Collection Accessibility," Library Technology Reports 48, no. 7 (2012).

42. Mulliken, "There Is Nothing Inherently Mysterious about Assistive Technology"; Marrall and Burmeister, "Conducting the Accessibility Audit"; Rebecca Arzola, "Collaboration between the Library and Office of Student Disability Services: Document Accessibility in Higher Education," Digital Library Perspectives 32, no. 2 (2016); Mary Case et al., Report of the ARL Joint Task Force on Services to Patrons with Disabilities (Chicago, IL: Association of Research Libraries, 2012); Heather Moorefield-Lang, Clayton Copeland, and Aisha Haynes, "Accessing Abilities: Creating Innovative Accessible Online Learning Environments and Putting Quality into Practice," Education for Information 32, no. 1 (2016).

43. "Best National University Rankings," U.S. News \& World Report (2018), retrieved from https://www.usnews. com/best-colleges/rankings/national-universities.

44. Islam, Agarwal, and Ikeda, "Knowledge Management for Service Innovation in Academic Libraries"; Candela Olle and Angel Borrego, "A Qualitative Study of the Impact of Electronic Journals on Scholarly Information Behavior," Library \& Information Science Research 32, no. 3 (2010).

45. Alan Dennis, Barbara Wixom, and Roberta Roth, Systems Analysis and Design (Hoboken, NJ: Wiley, 2018). 46. Matthew Miles and Michael Huberman, Qualitative Data Analysis: An Expanded Sourcebook, 2nd ed. (Thou- 
sand Oaks, CA: SAGE, 1994).

47. Andrew Cox et al., "Developments in Research Data Management in Academic Libraries: Towards an Understanding of Research Data Service Maturity," Journal of the Association for Information Science and Technology 68, no. 9 (2017).

48. Eddy Verbaan and Andrew Cox, "Occupational Subcultures, Jurisdictional Struggle, and Third Space: Theorizing Professional Service Responses to Research Data Management," Journal of Academic Librarianship 40, no. 3/4 (2014).

49. Devendra Potnis, Reynard Regenstreif-Harms, and Edwin Cortez, "Identifying Key Steps for Developing Mobile Applications \& Mobile Websites for Libraries," Information Technology and Libraries 35, no. 3 (2016); Devendra Potnis and Suzie Allard, "Training LIS Students as Mobile Technology Consultants for Libraries and Not-for-profit Organizations," Journal of Education for Library and Information Science 59, no. 4 (2018).

50. Samson, "Best Practices for Serving Students with Disabilities."

51. Samson, "Best Practices for Serving Students with Disabilities."

52. Hernon and Calvert, Improving the Quality of Library Services for Students with Disabilities.

53. Tripathi and Shukla, "Use of Assistive Technologies in Academic Libraries."

54. Yu Cui and Hao Jiao, "Organizational Justice and Management Trustworthiness during Organizational Change: Interactions of Benevolence, Integrity, and Managerial Approaches," Information Processing \& Management 56, no. 4 (2019).

55. Yeh and Walter, "Determinants of Service Innovation in Academic Libraries through the Lens of Disruptive Innovation."

56. Mark Bieraugel, "Managing Library Innovation Using the Lean Startup Method," Library Management 36, no. 4/5 (2015): 351-61.

57. Guder, "Equality through Access."

58. Brown and Freund, Services for users with disabilities.

59. Bieraugel, "Managing Library Innovation Using the Lean Startup Method."

60. Green and Gillespie, "Assistive Technologies in Academic Libraries."

61. Irene Gashurov and Curtis Kendrick, "Collaboration for Hard Times," Library Journal 138, no. 16 (2013).

62. Brannen, Milewski, and Mack, "Providing Staff Training and Programming to Support People with Disabilities."

63. Lusch and Nambisan, "Service Innovation." 